\title{
Effect of Ocimum sanctum in Sodium fluoride (NaF) induced Fluorosis in Rats: A Study with Respect to Antioxidant Enzymes and Fluorosis Markers
}

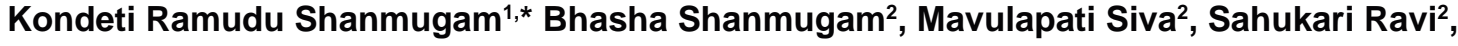 \\ Kesireddy Sathyavelu Reddy ${ }^{2}$ \\ ${ }^{1}$ Department of Zoology, PRR \& VS Government Degree College, Vidavalur, SPSR Nellore, Andhra Pradesh, INDIA. \\ ${ }^{2}$ Division of Molecular Biology and Ethnopharmacology, Department of Zoology, Sri Venkateswara University, Tirupati, \\ Andhra Pradesh, INDIA.
}

\begin{abstract}
Introduction: Fluoride contamination was observed in groundwater's of India, Pakistan, China, Indonesia and several other countries. In India the states like Andhra Pradesh, Telangana, Rajasthan, Haryana etc are contaminated with fluoride. Approximately 68 million people are suffering from fluorosis in India. The current study was done to know the antioxidant effect, anti-fluorosis and free radical scavenging property of Ocimum sanctum (OS). Methods: Superoxide dismutase (SOD), glutathione peroxidase (GPx), glutathione (GSH), glutathione reductase (GR), glutathione-s-transferase (GST), catalase (CAT), malondialdehyde (MDA), alanine aminotransferase (AAT), alkaline phosphatase (ALKP), aspartate aminotransferase (AST) and flurosis markers phosphorus $\left(P_{4}\right)$ and calcium $(\mathrm{Ca})$ are estimated in all groups. 1,1-diphenyl-2-picryl hydrazyl radical (DPPH), hydroxyl radical, hydrogen peroxide $\left(\mathrm{H}_{2} \mathrm{O}_{2}\right)$, Gas chromatography-mass spectrometry (GC-MS) was analyzed in methanolic extract of Ocimum sanctum. Results: SOD, GR, GSH, GPx CAT, activities and Ca levels are decreased in sodium fluoride (NaF) intoxicated rats. Whereas MDA, ALKP AST, AAT, and $\mathrm{P}_{4}$ levels are increased in $\mathrm{NaF}$ rats. However, Ocimum phenolic fraction treatment normalized the antioxidant enzymes, hepatic markers and flurosis markers in $\mathrm{NaF}$ intoxicated rats. $\mathrm{DPPH}, \mathrm{H}_{2} \mathrm{O}_{2}$ and hydroxyl radical of ocimum posses potent free radical scavenging activities. GC - MS studies of Ocimum sanctum showed the presence of many bioactive compounds like Caryophyllene oxide, 2-(2-Propenyl)-m-anisidine, 2H-Pyan-2-one, 5,6-Dihydro-4-(2-methyl-3-methylene1-buten-4-yl etc. Further, histopathological observations prove that ocimum protects the hepatic tissue from NaF intoxication. Conclusion: Our study proves that Ocimum sanctum phenolic fraction protects the hepatic tissue from $\mathrm{Na} F$ induced fluorosis in rats. Key words: Ocimum sanctum, Antioxidant Enzymes, Fluorosis markers, Liver markers, GC-MS analysis, Rats.
\end{abstract}

\section{INTRODUCTION}

Fluorosis is a worldwide health problem resulting from excess consumption of fluoride through food products, ingesting water, and industrial contaminants over a long period. Fluorosis affects teeth, liver, bone, kidney and other parts of human body. ${ }^{1,2}$ The major complications of fluorosis are dental fluorosisand skeletal fluorosis.

The practice of herbs to cure diseases was observed, since the dawn of civilization. Plant derived drugs are used to treat diseases like cancer, hepatitis, diabetes etc. The World Health Organization reported that traditional medicines like Ayurveda, sidda, unani use plant drugs to treat many health problems, because they are cheap and have no side effects. ${ }^{3,4}$

Ocimum sanctum is known as Tulasi. Ocimum sanctum has antiseptic, antimicrobial, antibactericidal, anti-inflammatory, antioxidant, antiulcer, anti-diarrheal and anti-diabetic
Submission Date: 26-06-2020; Revision Date: 09-08-2021; Accepted Date: 09-11-2021.

DOI: 10.5530/ijper.56.1.20 Correspondence: Dr. KR Shanmugam Assistant Professor Department of Zoology, PRR \& VS Government Degree College, Vidavalur, SPSR Nellore, Andhra Pradesh, INDIA E-mail: krshanmugamphd@ gmail.com

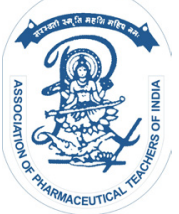

www.ijper.org 
properties. ${ }^{5-8}$ However, no study was carried on the antifluorosis property of Ocimum sanctum.

The aim of current study was to explore the antifluorosis, antioxidant activity of phenolic fraction of Ocimum sanctum in $\mathrm{NaF}$ toxicity rats. Our study is the first reported research investigation on the effect of phenolic fraction of Ocimum sanctum in fluorosis intoxicated rats.

\section{MATERIALS AND METHODS}

\section{Collection of plant material and Preparation of extracts}

Fresh and good Ocimum sanctum leaves are collected from Tirupati, A. P, India. The methanol extract of OS leaves are prepared as per the experimental protocol and was used for the study of free radical scavenging assay and GC MS analysis.

\section{Chemicals and reagents}

The chemicals are purchased from Himedia, Merck and Sigma-Aldrich.

\section{Extraction of Phenols from Ocimum Sanctum}

Phenolic fraction was extracted from Ocimum sanctum by the method of Magalhães et al. 2010. ${ }^{9}$

\section{Treatment Groups}

The young rats are divided into five groups.

Normal Control - Group I (NC): Six rats were treated with saline $(0.9 \% \mathrm{NaCl})$ for the period of 60 days.

Ocimum Control - Group II (Ot): Six rats were treated with Ocimum sanctum phenolic fraction $(100 \mathrm{mg} / \mathrm{kgBW})$ for the period of 60 days.

NaF treatment - Group III (Na F): Six rats were treated with sodium fluoride $(10 \mathrm{mg} / \mathrm{kgBW})$ dissolved in water for the period of 60 days.

$\mathrm{NaF}+$ Ocimum treatment - Group IV $(\mathrm{NaF}+\mathrm{Ot})$ : Six rats were treated with fluoride and Ocimum phenolic fraction for the period of 60 days.

$\mathrm{Na}$ F+ Vitamin treatment - Group V (NaF+Vit C): Six rats were treated with fluoride and Vitamin $\mathrm{C}$ for the period of 60 days.

After completion of last treatment i,e after sixty days treatment the rats are sacrificed by cervical dislocation and the liver tissue was collected in ice cold condition at $4^{\circ} \mathrm{C}$. The liver tissues are stored in deep freezer at $-80^{\circ} \mathrm{C}$ and later liver tissue was used for the estimation of antioxidant enzymes and other parameters. Blood sample was collected and used for analysis of liver markers and fluorosis makers.

\section{Estimations of Antioxidant Enzymes}

The antioxidant enzymes like superoxide dismutase (SOD), glutathione reductase (GR), glutathione -stransferase (GST), glutathione (GSH), catalase (CAT), glutathione peroxidase (GPx), activities, and MDA levels were estimated by the methods of Misra and Fridovich, ${ }^{10}$ Carlberg and Mannervik, ${ }^{11}$ Akerboom and Sies, ${ }^{12}$ Habig et al., ${ }^{13}$ Aebi, ${ }^{14}$ Flohe and Gunzler, ${ }^{15}$ Ohkawa et al., ${ }^{16}$ respectively.

Liver markers AST, ALT and ALP activities and Fluorosis markers Calcium, phosphorus levels are measured by standard kits.

\section{Estimation of Free radical scavenging activity}

DPPH, hydroxyl radical and hydrogen peroxide $\left(\mathrm{H}_{2} \mathrm{O}_{2}\right)$ radical activities of ocimum are estimated by the methods of Koleva et al., ${ }^{17}$ Halliwell et al..$^{18}$ and Rosen and Rauckman. ${ }^{19}$

\section{GC-MS Analysis for Bioactive compounds in Ocimum sanctum}

The phytochemical compounds like polar, semi polar, nonpolar and other compounds are present in Ocimum sanctum are recognized by GC- MS instrument. Gas Chromatography (GC) peaks obtained for compounds in this study are coupled with Mass Spectroscopy (MS) and compound structures present in ocimum are searched in National Institute of Standard and Technology (NIST) library and their structures are drawn by using Marvin Sketch a Chemo informatics (in silico) tool.

\section{Histopathological studies}

Liver tissue was immediately fixed in $4 \%$ paraformaldehyde phosphate buffer solution, after collection and process, it is used to assess the histopathology.

\section{Statistical study}

The results of our study are expressed as mean values \pm standard deviation. Statistical comparison was carried with five groups by using one-way ANOVA with Dunnett's multiple comparison Test. Differences are considered significant at $p<0.01$.

\section{RESULTS}

\section{Free radical scavenging assay of Ocimum sanctum}

DPPH activity expressed by methanolic extract and ascorbic acid are depicted in Figure 1. In the current study, Ocimum at the estimated concentrations showed significant DPPH scavenging activity, which shows free radical scavenging activity of Ocimum sanctum. 


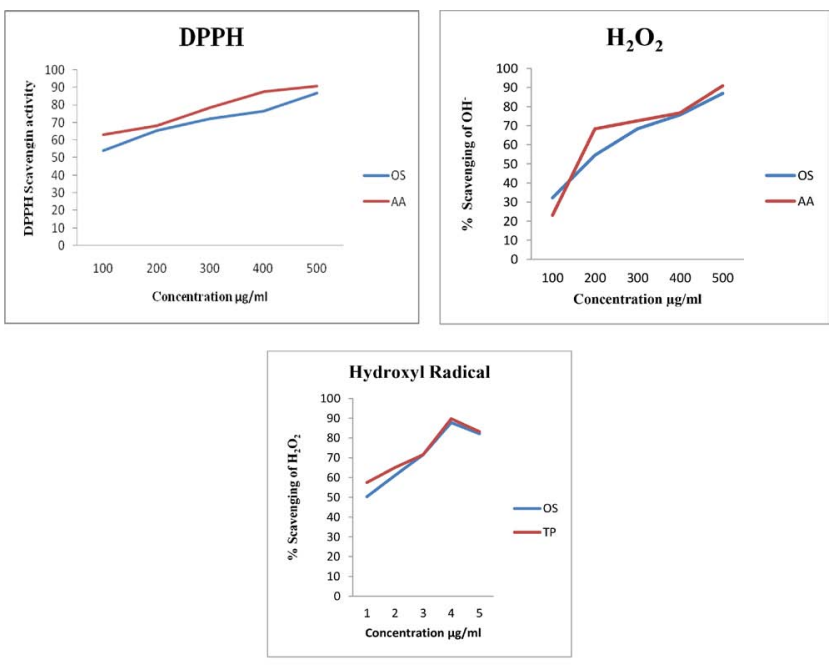

Figure 1: Free radical scavenging activity (DPPH, Hydrogen peroxide and Hydroxy Radicals) of metaholic extract of Ocimum sanctum with ascorbic acid and $\alpha$ tocopherol as standards.

The deoxyribose assay is a used to determine the hydroxyl radical activity of OS at different concentrations. (Figure 1). In the current study Ocimum sanctum at different concentrations posses significant hydroxyl radical scavenging potential.

Our results represents that the $\mathrm{H}_{2} \mathrm{O}_{2}$ scavenging activity of OS decreases than that of $\alpha$-tocopherol. Hydrogen peroxide converts to water due to the antioxidant compounds in the methanolic extract of OS.

\section{GC-MS Analysis for phytochemical profile identification}

GC-MS can discover many chemical compounds in the plants, food, and other samples. GC-MS analyse the structure of different bioactive compounds. In our analysis, we reported 14 compounds in Ocimum sanctum methanolic extract. GC-MS chromatogram reported the presence of bioactive compounds like 2H-Pyan-2-one, 5,6-Dihydro-4-(2-methyl-3-methylene1-buten-4-yl, Tricyclo[6.3.3.0] tetradec-4-ene, 10,13-dioxo, Perhydrohistrionicotoxin, 2-methylthio-2-depentyl,Trans-Z -à-Bisaboleneepoxide,2-(2-Propenyl)-m-anisidine, Patchoulene, 1,2,4-Triazol-4-amine 5-methyl-3-(3,5dimethylpyrazol-1-yl)-Naphthalene, 1,2,3,4,4a, 5,6,8aoctahydro-4a,8-dimethyl-2-(1-methylethenyl-, [2R-(2à,4aà,8aà)], Caryophyllene oxide, 9-Octadecenoic acid [Z], (tetrahydro-3-furanyi)methyl ester, 5-methyl3-(3,5-dimethylpyrazol-1-yl), 7,10-Octadecadienoic acid, methyl ester, Z-10-Methyl-11-tetradecen-1-ol propionate, Nonadecanoic acid, 18-oxo-, methyl ester, 4-Piperidineacetic acid, 5-ethylidene-2-[3-(2-hydroxyethyl)-1H- indol-2-yi]-à methylene-, methyl ester, [2S-(2à, 4à, 5E)]. (Figure 2, 3 and Table 1).

\section{Effect of Phenolic fraction of Ocimum on Hepatic antioxidant enzymes in Sodium Fluoride treatment rats}

In the current investigation, SOD, GPx, GR, CAT, activities, GSH levels are decreased in $\mathrm{NaF}$ intoxicated rats. However, with phenolic fraction of Ocimum supplementation in $\mathrm{Na} F$ rats, we observed significant elevation. But MDA content and GST activity are significantly increased in $\mathrm{NaF}$ intoxicated rats, however Ocimum supplementation decreased GST activity and MDA content in $\mathrm{NaF}$ rats. This shows the potential antioxidant effect of Ocimum (Figure 4).

\section{Effect of Phenolic fraction of Ocimum on Serum and Fluorosis markers in Fluorosis rats}

In the present study, AST, ALT, ALP activities and phosphorus levels are elevated in sodium fluoride intoxicated rats. But Calcium levels depleted in NAF rats. This indicates severe liver injury in Fluorosis condition. However phenolic fraction of Ocimum for 60 days supplementation significantly altered all the liver parameters and fluorosis markers in fluorosis rats. (Table 2).

\section{Effect of Phenolic fraction of Ocimum on Liver tissue in Fluorosis rats}

In this study, liver of normal rats and Ocimum treated rats exhibited normal central vein, hepatocytes and sinusoids. Where as in $\mathrm{NaF}$ rats, degeneration of central vein, hepatocytes and sinusoids are observed. However with Ocimum treatment for 60 days regenerated the central vein, hepatocytes and sinusoids in $\mathrm{NaF}$ toxicity rats. This study showed the hepatoprotective effect of Ocimum. (Figure 5).

\section{DISCUSSION}

The current investigation was carried to know the pharmacological effect of Ocimum sanctum phenolic faction in $\mathrm{NaF}$ induced fluoosis in rats.

DPPH activity is one of the important free radical scavenging assay which actually depend on the 1,1-diphenyl-2-picrylhydrazyl, which decolorize in presence of antioxidants, such asantioxidant compounds in Ocimum sanctum. ${ }^{20}$ The antioxidant compounds in Ocimum sanctum reacts with DPPH and convert it into1-1-diphenyl-2-picrylhydrazine and this scavenging activity was mainly depends on decolourization potential of methanolic extract of Ocimum sanctum. This assay have been used to estimate the free radical scavenging effect of 

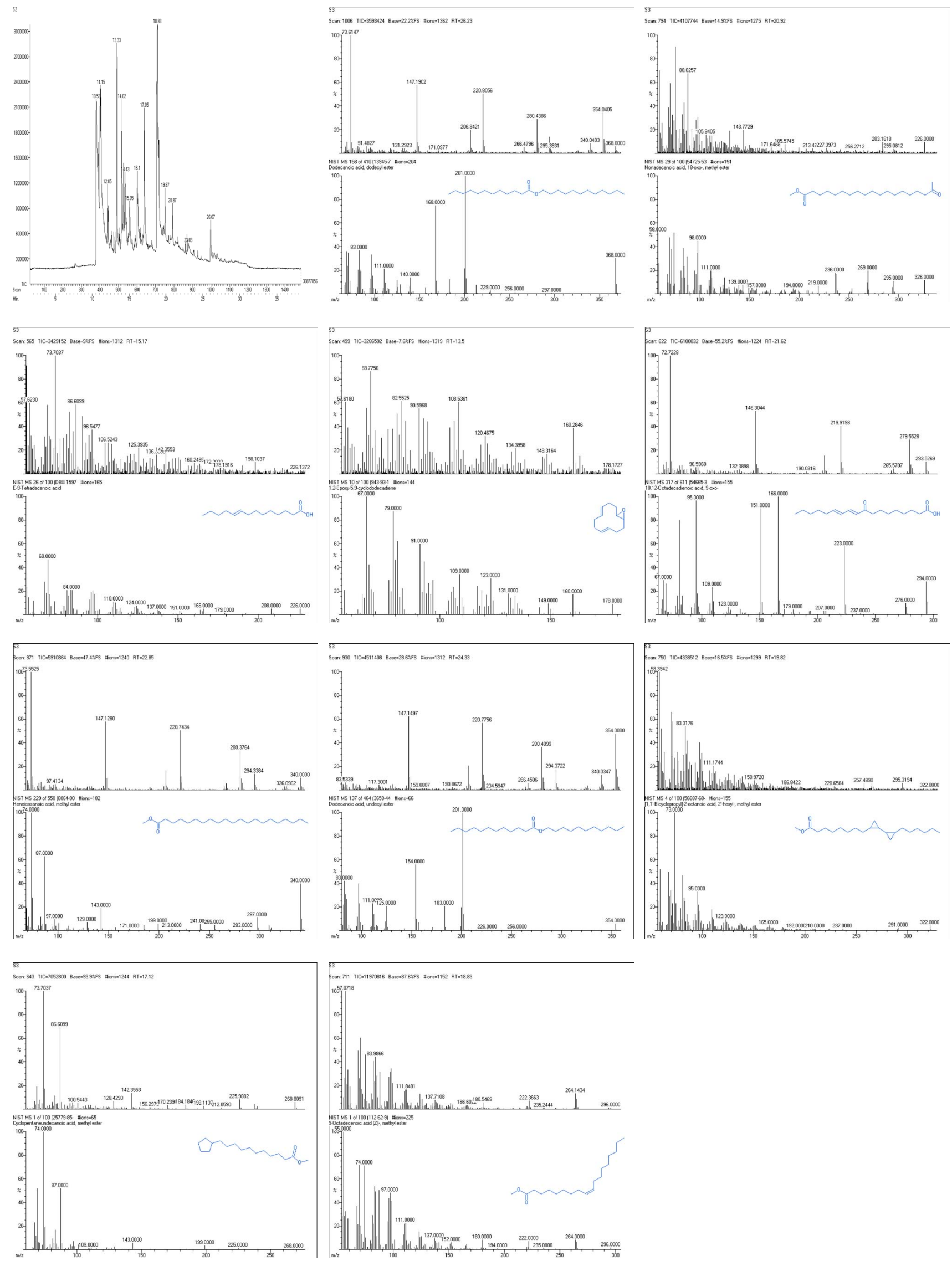

Figure 2: Pictographic Diagram of GC-MS Analysis of Ocimum sanctum 


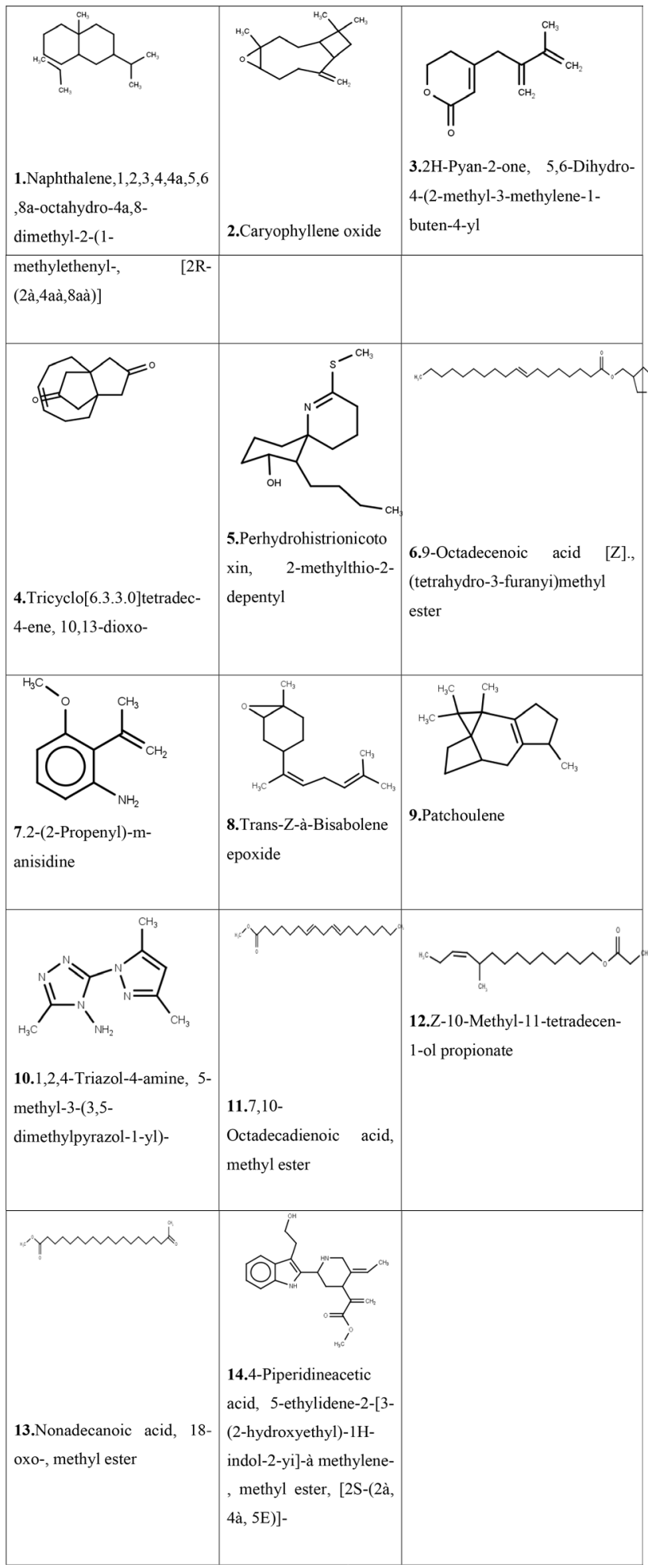

Figure 3: Chemical structures of the Bioactive compounds of Ocimum sanctum.

many medicinal plants. ${ }^{21}$ Antioxidant activity of Ocimum sanctum have been reported by many researchers. ${ }^{22,23}$ The standard ascorbic acid exhibits significant DPPH activity than OS methanolic extract.

\begin{tabular}{|c|c|c|c|}
\hline S.NO & $\begin{array}{l}\text { Name of the Bioactive } \\
\text { Compounds }\end{array}$ & R TIME & $\begin{array}{l}\text { Molecular } \\
\text { Weights }\end{array}$ \\
\hline 1 & $\begin{array}{c}\text { Naphthalene,1,2,3,4,4a,5,6,8a- } \\
\text { octahydro-4a,8-dimethyl- } \\
\text { 2-(1-methylethenyl-, } \\
\text { [2R-(2à,4aà,8aà)] }\end{array}$ & 12.05 & 238.459 \\
\hline 2 & Caryophyllene oxide & 13.33 & 220.356 \\
\hline 3 & $\begin{array}{c}\text { 2H-Pyan-2-one, 5,6-Dihydro-4- } \\
\text { (2-methyl-3-methylene-1-buten- } \\
\text { 4-yl }\end{array}$ & 11.15 & 178.231 \\
\hline 4 & $\begin{array}{c}\text { Tricyclo[6.3.3.0]tetradec-4-ene, } \\
\text { 10,13-dioxo- }\end{array}$ & 14.02 & 218.296 \\
\hline 5 & $\begin{array}{l}\text { Perhydrohistrionicotoxin, } \\
\text { 2-methylthio-2-depentyl }\end{array}$ & 17.05 & 269.45 \\
\hline 6 & $\begin{array}{c}\text { 9-Octadecenoic acid [Z]., } \\
\text { (tetrahydro-3-furanyi)methyl } \\
\text { ester }\end{array}$ & 26.08 & 366.586 \\
\hline 7 & 2-(2-Propenyl)-m-anisidine & 10.55 & 163.220 \\
\hline 8 & Trans-Z-à-Bisabolene epoxide & 14.43 & 220.356 \\
\hline 9 & Patchoulene & 15.05 & 216.368 \\
\hline 10 & $\begin{array}{c}\text { 1,2,4-Triazol-4-amine, 5-methyl- } \\
\text { 3-(3,5-dimethylpyrazol-1-yl)- }\end{array}$ & 16.1 & 192.226 \\
\hline 11 & $\begin{array}{c}\text { 7,10-Octadecadienoic acid, } \\
\text { methyl ester }\end{array}$ & 18.83 & 294.479 \\
\hline 12 & $\begin{array}{l}\text { Z-10-Methyl-11-tetradecen-1-ol } \\
\text { propionate }\end{array}$ & 19.87 & 282.468 \\
\hline 13 & $\begin{array}{l}\text { Nonadecanoic acid, 18-oxo-, } \\
\text { methyl ester }\end{array}$ & 20.87 & 326.521 \\
\hline 14 & $\begin{array}{l}\text { 4-Piperidineacetic acid, } \\
\text { 5-ethylidene-2-[3-(2- } \\
\text { hydroxyethyl)-1H-indol-2-yi]-à } \\
\text { methylene-, methyl ester, } \\
\text { [2S-(2à, 4à, 5E)]- }\end{array}$ & 23.03 & 354.450 \\
\hline
\end{tabular}

Hydrogen peroxide involves in various important physiological processes of cells. ${ }^{24}$ Methanolic extract of Ocimum sanctum convert the hydrogen peroxide to water. Ocimum sanctum showed potent $\mathrm{H}_{2} \mathrm{O}_{2}$ scavenging activity at different concentrations. ${ }^{18} \mathrm{DPPH}, \mathrm{H}_{2} \mathrm{O}_{2}$ and hydroxyl radical scavenging activity of methanolic extract of Ocimum sanctum showed lower effect than standard. The standards i,e ascorbic acid and alpha tocopherol are completely independent compounds hence, they posses good antioxidant effect at different concentrations than methanolic extract of Ocimum sanctum. (Figure 1). Free radical scavenging effects are due the presence of phytochemicals and secondary metabolites like phenolic, flavonoids, and other compounds ${ }^{25}$ in Ocimum sanctum. The importance of free radical scavenging activity is to estimate the antioxidant effect because Ocimum sanctum has many antioxidant compounds. ${ }^{26}$ 

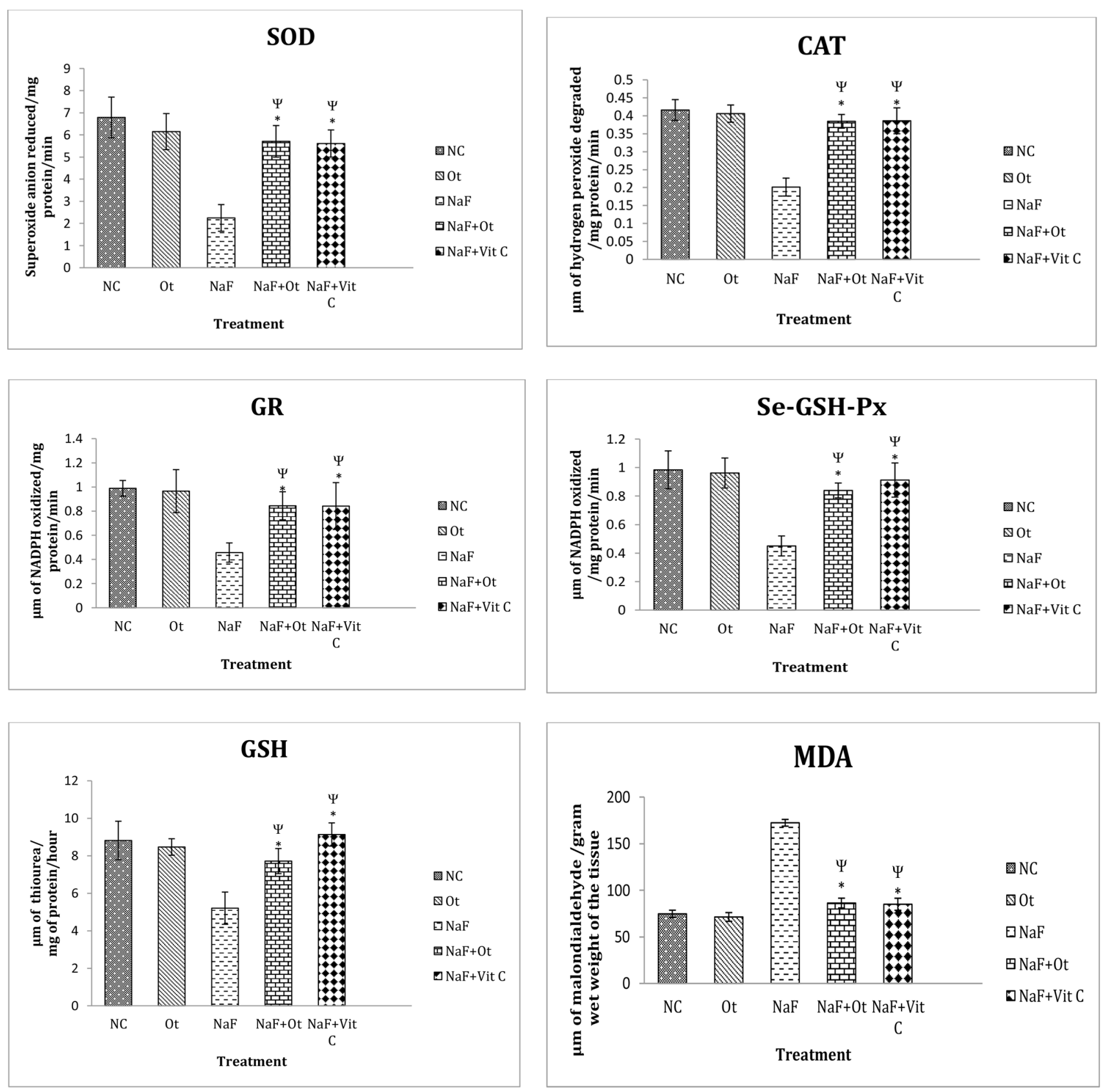

Figure 4: Impact of Ocimum sanctum phenolic fraction on SOD, CAT, GR, GPx, activities and GSH, MDA levels in the liver tissues of Normal and Fluorosis rats. Data are expressed as means $\pm \operatorname{SD}(n=6)$. * The values are significant compared to the following: control ( $\left.{ }^{*} p<0.01\right)$, Fluorosis $\left({ }^{*} p<0.01\right)$ (Dunnett's multiple comparison tests).

In our study GC-MS analysis of Ocimum sanctum reports many bioactive compounds. These bioactive compounds were recognized through mass spectrum analysis connected with GC. The unknown peaks obtained from the chromatogram are examined with the database of known spectrum of components kept in GC-MS library. The bioactive compounds, which are detected by the GC-MS are shown in Table 1.

In our analysis, we have identified 14 compounds in Ocimum sanctum methanolic extract. The compounds are 5-methyl-3-(3,5-dimethylpyrazol-1-yl)-Naphthalene, [2R-(2à,4aà,8aà)], Caryophylleneoxide, 5,6-Dihydro-4-(2methyl-3-methylene-1-buten-4-yl, 9-Octadecenoic acid [Z], (tetrahydro-3-furanyi)methyl ester, 2H-Pyan-2-one, Tricyclo[6.3.3.0] tetradec-4-ene, 10,13-dioxo, Perhydrohistrionicotoxin, 2-methylthio-2-depentyl,Trans-Z-à-Bisabo leneepoxide,2-(2-Propenyl)-m-anisidine, Patchoulene, 1,2,4-Triazol-4-amine, 5-methyl-3-(3,5-dimethylpyrazol1-yl), 1,2,3,4,4a,5,6,8a-octahydro-4a,8-dimethyl-2-(1-methyl ethenyl-,7,10-Octadecadienoic acid, methyl ester, Z-10- 


\begin{tabular}{|c|c|c|c|c|c|}
\hline Groups & $\begin{array}{c}\text { AST } \\
\text { (IU/L) }\end{array}$ & $\begin{array}{c}\text { ALT } \\
\text { (IU/L) }\end{array}$ & $\begin{array}{l}\text { ALP } \\
\text { (IU/L) }\end{array}$ & $\begin{array}{c}\mathrm{Ca} \\
\text { (IU/L) }\end{array}$ & $\begin{array}{c}P P \\
\text { (mg/dL }\end{array}$ \\
\hline Group I & 586.82 & 94.12 & 414 & 11.31 & 14.24 \\
\hline (NC) & $( \pm 12.48)$ & $( \pm 6.68)$ & $( \pm 8.26)$ & $( \pm 1.69)$ & $( \pm 1.24)$ \\
\hline Group II & 435 & 92.535 & 285 & 11.82 & 13.84 \\
\hline (Ot) & $( \pm 12.46)$ & $( \pm 10.14)$ & $( \pm 10.42)$ & $( \pm 1.46)$ & $( \pm 1.16)$ \\
\hline Group III & $606.442^{*}$ & $101.642^{*}$ & $614^{*}$ & $8.2^{*}$ & $16.82^{*}$ \\
\hline$(\mathrm{NaFt})$ & $( \pm 18.48)$ & $( \pm 8.68)$ & $( \pm 11.28)$ & $( \pm 1.72)$ & $( \pm 1.36)$ \\
\hline Group IV & $72.267^{*}$ & $67.348^{*}$ & $180^{*}$ & $10.2^{*}$ & $13.26^{*}$ \\
\hline$(\mathrm{NaF}+\mathrm{Ot})$ & $( \pm 4.62)$ & $( \pm 4.52)$ & $( \pm 8.42)$ & $( \pm 1.82)$ & $( \pm 1.32)$ \\
\hline Group V & $66.731^{*}$ & 51.189* & $151^{*}$ & $11.22^{*}$ & $13.86^{*}$ \\
\hline$(\mathrm{NaF}+\mathrm{Vit} \mathrm{C})$ & $( \pm 3.14)$ & $( \pm 4.12)$ & $( \pm 6.14)$ & $( \pm 1.12)$ & $( \pm 1.64)$ \\
\hline
\end{tabular}

All the values are means \pm SD of six individual observations.

* Significant at $p<0.001$ with respect to normal control.

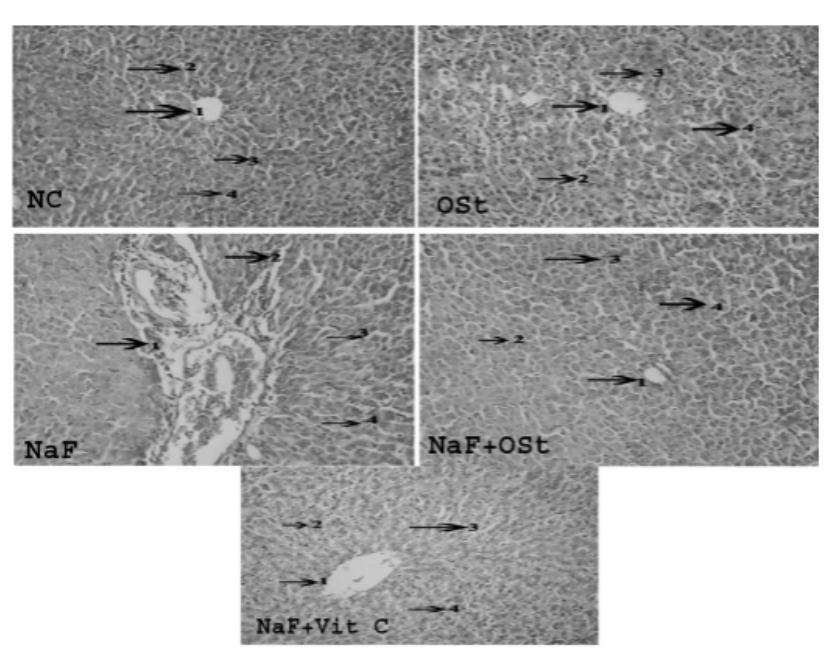

Figure 5: Impact of Ocimum on Liver tissue in NaF intoxicated Fluorosis rats.

1. Normal Control (Nc). 1. Normal central vein, 2. Normal hepatocytes, 3.Normal sinusoids, 4. Normal nucleus. 2. Ocimum treatment (OSt): 1.Nomal cenntral vein, 2. Normal hepatocytes, 3. Normal sinusoids, 4. Normal nucleus. 3.Sodium fluoride (NaF) 1. Degeneration of central vein, 2. Degeneration of hepatocytes, 3. Degeneration of sinusoids, 4. Degeneration of nucleus. 4. Sodium fluoride + Ocimum treatment $(\mathbf{N a F}+\mathbf{O S t})$ showed 1. Regeneration of central vein, 2. Regeneration of hepatocytes, 3.Regeneration of sinusoids, 4. Regeneration of nucleus. 5. Sodium fluoride +Vitamin $\mathbf{C}$ treatment (NaF+Vit $\mathbf{C})$ 1. Regeneration of central vein, 2. Regeneration of hepatocytes, 3.Regeneration of sinusoids, 4. Regeneration of nucleus.

Methyl-11-tetradecen-1-ol propionate, Nonadecanoic acid, 18-oxo-, methyl ester, 4-Piperidineacetic acid, 5-ethylidene-2-[3-(2-hydroxyethyl)-1H-indol-2-yi]-à methylene-, methyl ester, [2S-(2à, 4à, 5E)]-These compounds may have pharmacological properties, which are unexplored (Figure 2,3 and Table 1).

In the present investigation, the antioxidant enzymes like SOD, GPx, GR, CAT, GSH are depleted in sodium fluoride induced fluorosis rats. Our study reported that depletion of these antioxidant enzymes in $\mathrm{Na} \mathrm{F}$ treatment rats. This may be due to the oxidative stress and excess free radicals production in $\mathrm{NaF}$ intoxicated rats. However, OS phenolic fraction treatment in $\mathrm{NaF}$ rats for 60 days reversed these antioxidant enzymes. Ocimum has many pharmacological properties like antioxidant, hepatoprotective and antimicrobial and other properties. Ocimum has many bioactive and pharmacological compounds, these may be responsible for the up regulation of antioxidant enzymes in $\mathrm{NaF}$ rats. Ocimum treatment considerably recovered the activities of antioxidant enzymes in $\mathrm{NaF}$ intoxicated rats. (Figure 4).

Oxidative stress is reported to be associated with more than 100 diseases like cancer, diabetes and hepatitis. There is a strong relationship between TBA (thiobarbituric acid-reactive substances) and products that reflect oxidative damage to DNA. MDA levels depleted in $\mathrm{NaF}$ rats, but with Ocimum treatment reversed back MDA levels, near to normal. This shows the antiperoxidative activity. Hepato toxicity is the condition of oxidative stress in liver generating reactive oxygen species as a result, liver MDA levels increased in $\mathrm{NaF}$ rats. However, Ocimum treatment, MDA levels decreased in hepatitis rats. (Figure 4).

In rats, which received $\mathrm{NaF}$ for 60 days, showed liver damage and also disturbance of liver cell metabolism which lead to alterations in the activities of many enzymes. Serum enzymes AST, ALP and ALT are markers of liver toxicity and their higher levels are representation of cellular damages and loss of hepatic 
cell membrane. In the current study, we reported elevation in AST, ALT and ALP activities in NaF intoxicated rats. Our report showed fluorosis leads to hepatic cellular dysfunction, which results in the upregulation of liver markers. However with Ocimum supplementation these serum markers are depleted in $\mathrm{NaF}$ rats. Based on our results, the Ocimum sanctum methanolic extract have hepatoprotective potential. OS may reduce the formation of toxic free radicals and reduces the hepatocellular injury in $\mathrm{NaF}$ rats (Table 2). Calcium and Phosphorus are important to humans, because, they help in the formation of bone. In the present study, we observed depleted calcium levels and elevated phosphorus levels in sodium fluoride intoxicated rats. These alterations in calcium and phosphorus levels are due changes in the metabolism of phosphorus and calcium. Whereas Ocimum treatment in $\mathrm{NaF}$ rats, for 60 days, these fluorosis markers normalized to near normal levels. (Table 2).

In the current investigation, we reported that in normal control rats, Ocimum treated rats the liver architecture is normal. Whereas in fluorosis rat liver, degeneration of central vein, hepatocytes, sinusoids and blood coagulation are observed. But with Ocimum treatment in fluorosis rats, regeneration of central vein, hepatocytes and sinusoids are observed. Histopathological studies also prove that the hepatoprotective effect of Ocimum in $\mathrm{NaF}$ rats. (Figure 5).

\section{CONCLUSION}

The current study proved that phenolic fraction of Ocimum sanctum protects the hepatic tissue from sodium fluoride intoxication in albino rats. We also reported that antioxidant enzymes, hepatic markers and flurosis markers are normalized with Ocimum treatment in Fluorosis rats. GC-MS analysis reported many bioactive compounds in Ocimum sanctum and these compounds may responsible for anti-fluorosis effect and antioxidant effects. This is the first study on the effect of phenolic fraction of Ocimum sanctum in fluorosis rats.

\section{ACKNOWLEDGEMENT}

The Corresponding author is thankful to the University Grants Commission, New Delhi, India for the approve of the Major Research Project 2013-36027 dated 15/10/2015.

\section{CONFLICT OF INTEREST}

The authors declare that there is no conflict of interest.

\section{ABBREVIATIONS}

OS: Ocimum sanctum; SOD: Superoxide dismutase; GPx: Glutathione peroxidase; GSH: Glutathione; GR: Glutathione reductase; GST: Glutathione-s-transferase; CAT: Catalase; MDA: Malondialdehyde; AAT: Alanine aminotransferase; ALKP: Alkaline phosphatase; AST: Aspartate aminotransferase; P4: Phosphorus; Ca: Calcium; DPPH: 1,1-diphenyl-2-picryl hydrazyl radical; $\mathbf{H}_{2} \mathbf{O}_{2}$ : Hydrogen peroxide; GC-MS: Gas chromatography-mass spectrometry; MS: Mass Spectroscopy; NIST: National Institute of Standard and Technology; TBA: thiobarbituric acid-reactive substances.

\section{REFERENCES}

1. Dharmaratne RW. Fluoride in drinking water and diet: the causative factor of chronic kidney diseases in the North Central Province of Sri Lanka. Environ Health Prev Med. 2015;20(4):237-42. doi: 10.1007/s12199-015-0464-4, PMID 25916575.

2. Chachra D, Turner $\mathrm{CH}$, Dunipace AJ, Grynpas MD. The effect of fluoride treatment on bone mineral in rabbits. Calcif Tissue Int. 1999;64(4):345-51. doi: 10.1007/s002239900630, PMID 10089229.

3. Loera JA, Reyes-Ortiz C, Kuo YF. Predictors of complementary and alternative medicine use among older Mexican Americans. Complement Ther Clin Pract. 2007;13(4):224-31. doi: 10.1016/j.ctcp.2007.03.002, PMID 17950177.

4. Sindhia VR, Bairwa R. Plant review: Butea monosperma. Int J Pharmaceu Clini Res. 2010;2(2):90-4.

5. Khare CP. Indian medicinal plants, an illustrated dictionary. Berlin: SpringerVerlag; 2007.

6. Soni A, Sosa S. Phytochemical analysis and free radical scavenging potential of herbal and medicinal plant extracts. J Pharmacogn Phytochem. 2013;2(4):22-9.

7. Prakash J, Gupta SK. Chemopreventive activity of Ocimum sanctum seed oil. J Ethnopharmacol. 2000;72(1-2):29-34. doi: 10.1016/s03788741(00)00194-x, PMID 10967450.

8. Shanmugam KR, Shanmugam B, Subbaiah GV, Ravi S, Reddy KS. Medicinal plants and bioactive compounds for diabetes management: important advances in drug discovery. Curr Pharm Des. 2021;27(6):763-74. doi: 10.21 74/1381612826666200928160357, PMID 32988345

9. Magalhães PJ, Vieira JS, Gonçalves LM, Pacheco JG, Guido LF, Barros AA. Isolation of phenolic compounds from hop extracts using polyvinyl polypyrrolidone: characterization by high-performance liquid chromatographydiode array detection-electrospray tandem mass spectrometry. J Chromatogr A. 2010;1217(19):3258-68. doi: 10.1016/j.chroma.2009.10.068, PMID 19913228.

10. Misra HP, Fridovich I. The role of superoxide anion in the autoxidation of epinephrine and a simple assay for superoxide dismutase. J Biol Chem. 1972;247(10):3170-5. PMID 4623845.

11. Carlberg I, Mannervik B. Glutathione reductase. Methods Enzymol. 1985;113:484-90. doi: 10.1016/s0076-6879(85)13062-4, PMID 3003504.

12. Akerboom TP, Sies H. Assay of glutathione, glutathione disulfide, and glutathione mixed disulfides in biological samples. Methods Enzymol. 1981;77:373-82. doi: 10.1016/s0076-6879(81)77050-2, PMID 7329314.

13. Habig WH, Pabst MJ, Jakoby WB. Glutathione S-transferases. The first enzymatic step in mercapturic acid formation. J Biol Chem. 1974;249(22):7130-9. doi: 10.1016/S0021-9258(19)42083-8, PMID 4436300.

14. Aebi H. Catalase in vitro. Methods Enzymol. 1984;105:121-6. doi: 10.1016/ s0076-6879(84)05016-3, PMID 6727660.

15. Flohé L, Günzler WA. Assays of glutathione peroxidase. Methods Enzymol. 1984;105:114-21. doi: 10.1016/s0076-6879(84)05015-1, PMID 6727659. 
16. Ohkawa H, Ohishi N, Yagi K. Assay for lipid peroxides in animal tissues by thiobarbituric acid reaction. Anal Biochem. 1979;95(2):351-8. doi: 10.1016/0003-2697(79)90738-3, PMID 36810

17. Koleva II, Van Beek TA, Linssen JP, De Groot A, Evstatieva LN. Screening of plant extracts for antioxidant activity: A comparative study on three testing methods. Phytochem Anal. 2002;13(1):8-17. doi: 10.1002/pca.611, PMID 11899609.

18. Halliwell B, Gutteridge JM, Aruoma OI. The deoxyribose method: A simple "test-tube" assay for determination of rate constants for reactions of hydroxyl radicals. Anal Biochem. 1987;165(1):215-9. doi: 10.1016/00032697(87)90222-3, PMID 3120621.

19. Rosen GM, Rauckman EJ. [23] Spin trapping of superoxide and hydroxyl radicals. Methods Enzymol. 1984;105:198-209. doi: 10.1016/S00766879(84)05026-6.

20. Kumarasamy Y, Byres M, Cox PJ, Jaspars M, Nahar L, Sarker SD. Screening seeds of some Scottish plants for free radical scavenging activity. Phytother Res. 2007;21(7):615-21. doi: 10.1002/ptr.2129, PMID 17357975.
21. Jao C, Ko W. 1,1-diphenyl-2-picrylhydrazyl (DPPH) radical scavenging by protein hydrolyzates from tuna cooking juice. Fish Sci. 2002;68(2):430-5. doi: 10.1046/j.1444-2906.2002.00442.x.

22. Kath RK, Gupta RK. Antioxidant activity of hydroalcoholic leaf extract of Ocimum sanctum in animal models of peptic ulcer. Indian J Physiol Pharmacol. 2006;50(4):391-6. PMID 17402269.

23. Mishra P, Mishra S. Study of antibacterial activity of Ocimum sanctum Extract against Gram Positive and Gram Negative Bacteria. Am J Food Technol. 2011;6(4):336-41. doi: 10.3923/ajft.2011.336.341.

24. D'Autréaux B, Toledano MB. ROS as signalling molecules: Mechanisms that generate specificity in ROS homeostasis. Nat Rev Mol Cell Biol. 2007;8(10):813-24. doi: 10.1038/nrm2256, PMID 17848967.

25. Javanmardi J. Antioxidant activity and total phenolic content of Iranian Ocimum accessions. Food Chem. 2003;83(4):547-50. doi: 10.1016/S03088146(03)00151-1.

26. Abu Bakar MF, Mohamed M, Rahmat A, Fry J. Phytochemicals and antioxidant activity of different parts of bambangan (Mangifera pajang) and tarap (Artocarpus odoratissimus). Food Chem. 2009;113(2):479-83. doi: 10.1016/j.foodchem.2008.07.081.

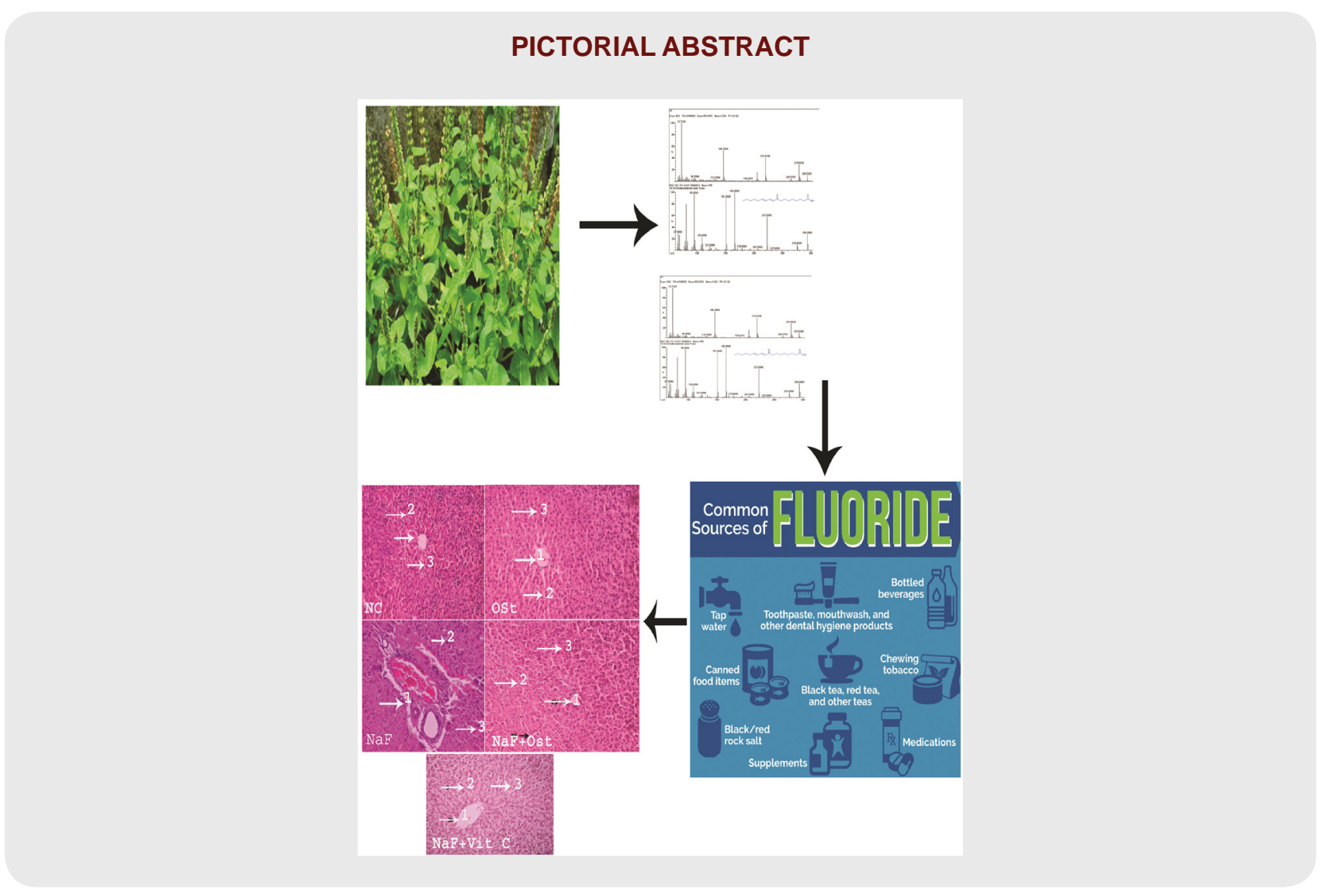

Cite this article: Shanmugam KR, Shanmugam B, Siva M, Ravi S, Reddy KS. Effect of Ocimum sanctum in Sodium fluoride (NaF) induced Fluorosis in Rats: A Study with Respect to Antioxidant Enzymes and Fluorosis Markers. Indian J of Pharmaceutical Education and Research. 2022;56(1):175-83. 